NBER WORKING PAPER SERIES

\title{
TARGETING RULES VS. INSTRUMENT RULES FOR MONETARY POLICY: WHAT IS WRONG WITH MCCALLUM AND NELSON?
}

\author{
Lars E.O. Svensson \\ Working Paper 10747 \\ http://www.nber.org/papers/w10747 \\ NATIONAL BUREAU OF ECONOMIC RESEARCH \\ 1050 Massachusetts Avenue \\ Cambridge, MA 02138 \\ September 2004
}

I am grateful to Bennett McCallum, Edward Nelson, and Michael Woodford for comments and discussions, and to Kathleen Hurley for editorial and secretarial assistance. Remaining errors and expressed views are my own responsibility. The views expressed herein are those of the author(s) and not necessarily those of the National Bureau of Economic Research.

(C)2004 by Lars E.O. Svensson. All rights reserved. Short sections of text, not to exceed two paragraphs, may be quoted without explicit permission provided that full credit, including () notice, is given to the source. 
Targeting Rules vs. Instrument Rules for Monetary Policy: What is Worng with McCallum and Nelson?

Lars E.O. Svensson

NBER Working Paper No. 10747

September 2004

JEL No. E42, E52, E58

\begin{abstract}
$\underline{\text { ABSTRACT }}$
McCallum and Nelson's (2004) criticism of targeting rules for the analysis of monetary policy is rebutted. First, McCallum and Nelson's preference to study the robustness of simple monetary-policy rules is no reason at all to limit attention to simple instrument rules; simple targeting rules may have more desirable properties. Second, optimal targeting rules are a compact, robust, and structural description of goal-directed monetary policy, analogous to the compact, robust, and structural consumption Euler conditions in the theory of consumption. They express the very robust condition of equality of the marginal rates of substitution and transformation between the central bank's target variables. Third, under realistic information assumptions, the instrument-rule analogue to any targeting rule that McCallum and Nelson have proposed results in very large instrument-rate volatility and is also for other reasons inferior to a targeting rule.

Lars E.O. Svensson

Department of Economics

Fisher Hall

Princeton University

Princeton, NJ 08544-1021

and NBER

svensson@princeton.edu
\end{abstract}




\section{Introduction}

My good friends Ben McCallum and Ed Nelson have written a paper, McCallum and Nelson [28], with arguably a somewhat destructive purpose. They attempt to contradict the arguments in favor of targeting rules rather than instrument rules in positive and normative analysis of monetary policy that I have presented in Svensson [40] and previous papers, for instance, [36] and [37]. In their concluding section, they suggest that Svensson [40] "does not develop any compelling reasons for preferring targeting rules over instrument rules." They seem to believe that the concept of targeting rules is unnecessary, and that instrument rules are all that is needed in monetary-policy analysis.

In their struggle against targeting rules, however, Ben and Ed seem to face an uphill battle. There is now a rapidly growing literature by many authors that successfully apply targeting rules to monetary-policy analysis. This literature includes recent contributions by Benigno and Benigno [2], Benigno and Woodford [3] and [4], Checchetti [10] and [11], Checchetti and Kim [12], Evans and Honkapohja [13], Giannoni and Woodford [14]-[16], Kuttner [22], Mishkin [31], Onatski and Williams [32], Preston [33], Walsh [46]-[48], Woodford [49], and others. In the first drafts of Woodford's [50] book, there were no targeting rules; in the final, published version, targeting rules are prominent. In 1998, at a distinguished NBER conference on monetary-policy rules (Taylor [45]), Rudebusch and Svensson [34] was the only paper using targeting rules; in 2003, at an equally distinguished NBER conference on inflation targeting (Bernanke and Woodford [6]), several papers used targeting rules, and no paper used a simple instrument rule as a model of inflation targeting. A Google search with the string " ‘targeting rules' and monetary" gave about 1700 results in April 2004 and about 2100 results in August 2004. There are hence more papers than mine -indeed, some books - that Ben and Ed may want to take issue with. ${ }^{1}$

An instrument rule is a formula for setting the central bank's instrument rate as given function of observable variables. A simple instrument rule makes the instrument rate a simple function of a few observable variables. The best-known example of a simple instrument rule is the Taylor rule, where the instrument rate is a linear function of the inflation gap (between inflation and an inflation target) and the output gap (between output and potential output). Another example is a formula for adjusting the monetary base due to McCallum [23] and Meltzer [29]. ${ }^{2}$

\footnotetext{
${ }^{1}$ Sims [35] and Aizenman and Frenkel [1] provide early discussions of targeting rules (the former without using the name).

${ }^{2}$ Svensson [42] provides a compact and general definition of targeting rules and instrument rules. An explicit instrument rule is an instrument rule where the instrument is a function of predetermined variables only. An implicit instrument rule is an instrument rule where the instrument is related to a non-predetermined variable. An implicit instrument rule is an equilibrium condition, where several variables are simultaneously determined. This makes the practical implementation of implicit instrument rules more complicated than that of explicit instrument rules (see
} 
A (specific) targeting rule specifies a condition to be fulfilled by the central bank's target variables (or forecasts thereof). A real-world example of a simple targeting rule is the one that has been applied by the Bank of England, Sweden's Riksbank, and the Bank of Norway (Goodhart [17]; Svensson [39]; Svensson, Houg, Solheim and Steigum [43]): The two-year-ahead inflation forecast shall equal the inflation target. More precisely, the instrument rate shall be set such that the twoyear-ahead inflation forecast equals the inflation target. An optimal targeting rule is a first-order condition for optimal monetary policy. ${ }^{3}$

Ben and Ed explain that "we are more attracted to analysis with instrument rules than with targeting rules" (section 2). They imply that the main reason is that "an attractive approach to policy design ... is to search for an instrument rule that performs at least moderately well — avoiding disasters - in a variety of plausible models." Thus, Ben and Ed are attracted to simple and robust instrument rules; they agree with Svensson [40] that a complex optimal instrument rule is not practical. The idea of a robust and simple instrument rule is further developed in McCallum [23] and $[24]$.

A simple and robust monetary-policy rule is indeed an attractive idea. There is always some uncertainty about the true model of the transmission mechanism of monetary policy, and monetary policy is always conducted under considerable uncertainty of different kinds. A simple and robust monetary-policy rule gives the central bank an option that it can fall back on in difficult times. A central bank that knows nothing except current inflation and some estimate of the current output gap can always fall back on a Taylor rule. If the bank does not trust its information about inflation and the output gap, but data on monetary aggregates is more easily accessible or more reliable, the central bank can fall back further on Friedman's rule of $k$ percent money growth.

But several facts stand in the way of Ben and Ed's attraction to simple instrument rules. First, the fact is that nothing says that a simple and robust monetary-policy rule must be an instrument rule. For instance, Friedman's $k$ percent is a targeting rule! The $k$ percent refers to a broad monetary aggregate, such as M3. This is an (intermediate) target variable, not an instrument. It reacts with a lag of a quarter or so to changes in the central bank's instrument (the instrument rate or the monetary base). The way to implement Friedman's $k$ percent is to make forecasts of broad money growth for the next quarter and set the current instrument rate such that the one-quarter-ahead

footnote 10). Any given equilibrium is consistent with a continuum of implicit instrument rules.

3 Strangely, Ben and Ed seem to believe that no central bank is using a targeting rule and that a central bank needs to announce an explicit loss function in order to use a targeting rule. Obviously, neither of these beliefs are correct, as this paragraph shows. 
money-growth forecast equals $k$ percent (Svensson [37]). ${ }^{4}$ The simple monetary-policy rule used by the Bank of England, the Riksbank, and the Bank of Norway - already mentioned above - is also a targeting rule. Walsh [48] have recently demonstrated an equivalence between the robust-control policies of Hansen and Sargent [19] and [20] and the optimal targeting rules derived by Giannoni and Woodford [14] and [15]. ${ }^{5}$

Second, the fact is that central banks normally do not use the fallback options of the simple instrument rules of Taylor or of McCallum and Meltzer, or even the simple targeting rule of Friedman's $k$ percent. With improved understanding of the transmission mechanism of monetary policy, increased experience, and better designed objectives for monetary policy, central banks believe that they can do better than follow these mechanical simple rules. They have developed complex decision processes, where huge amounts of data are collected, processed, and analyzed (see Brash [8] and Svensson [38]). They construct forecasts of their target variables, typically inflation and the output gap, conditional on their view of the transmission mechanism, their estimate of the current state of the economy and the development of a number of exogenous economic variables, and alternative instrument-rate paths. They select and implement an instrument rate or an instrument-rate path such that the corresponding forecasts of the targeting variables "look good" relative to the objectives of the central bank. I have called this monetary-policy process "forecast targeting." It is a decision process and implementation of monetary policy that is very different from the mechanical application of the simple instrument rules that Ben and Ed favor. Advanced central banks attempt to do better, to fulfill their objectives as well as possible, to optimize. I am advocating targeting rules as a better way to describe and prescribe this kind of monetary policy than the simple instrument rules. Targeting rules are one way to make "look good" precise. ${ }^{6}$

\footnotetext{
4 A broad monetary aggregate such as M3 is to a large extent endogenously determined by demand and supply of broad money and an endogenous multiplier between broad money and the monetary base. It reacts with a lag of a quarter or so to central-bank adjustments of the instrument rate or the monetary base and is subject to various intervening shocks during that lag. The central bank does hence not have complete control over broad money; therefore, it is not an instrument of monetary policy. Even if the money-growth forecast is on target, actual money growth will ex post deviate from $k$ percent due to unanticipated shocks and imperfections in the forecasts.

${ }^{5}$ In some of the literature mentioned above, the instrument rate is also a target variable (that is, an argument of the loss function). In such cases, the instrument rate appears in the targeting rule, and the targeting rule is also an implicit instrument rule. Some of the literature, for instance, Walsh [48], follow Giannoni and Woodford [14] and [15] and frequently refer to such targeting rules as instrument rules, which is a source of some confusion. A good test of whether a rule is fundamentally a targeting rule or an instrument rule is to let the weight on the instrument rate in the loss function go to zero. If the instrument rate then vanishes from the rule, the rule has better be called a targeting rule.

${ }^{6}$ Ben and Ed note (section 4) that many central-bank publications refer to simple instrument rules. But this merely demonstrates how the concept of simple instrument rules have previously dominated the monetary-policy debate (for instance, as noted, in Taylor [45]). It does not imply that central banks conduct monetary policy by implementing simple instrument rules. They also note that the Reserve Bank of New Zealand has used a particular instrument rule in generating forecasts in the so-called Forecasting and Policy System (Black, Cassino, Drew, Hansen, Hunt, Rose and Scott [7]). But, as far as I know, the instrument path generated by the instrument rule is subject to considerable judgemental adjustment, especially for the first few quarters. Furthermore, the instrument-rate path and the inflation and output-gap forecasts generated can be seen as reference paths and forecasts, used as an input
} 
Third, while central banks in a number of countries have developed this approach of forecast targeting to monetary policy, essentially the implementation of inflation targeting that started in a few countries in the early 1990s and has since spread to a large number of countries, the monetarypolicy outcome in a number of countries has been extremely good. The last decade has seen an unprecedented monetary and real stability with low inflation in a number of countries. This makes it even more important, I believe, to develop the tools and definitions through which this kind of monetary policy can be best understood. ${ }^{7}$

Ben and Ed have one somewhat constructive contribution in their paper. They provide further analysis of the proposition, previously put forward in McCallum [24, p. 1493] and McCallum and Nelson [27], that there is a useful instrument-rule analogue, with a very large response coefficient, to any targeting rule. In particular, they maintain that this large response coefficient, counter to what is argued in Svensson and Woodford [44], Svensson [40], and, for a related case, in Bernanke and Woodford [5], does not imply higher volatility of the instrument rate, even if the central bank makes some realistic errors in determining the arguments of the instrument rule. However, as we shall see, under reasonable information assumptions, Ben and Ed are wrong. A large response coefficient does indeed make the instrument rate very volatile. Only under very strange information assumptions is there no extra volatility. Even if they were right on this volatility issue, there still seems to be no point with their proposed instrument-rule analogue. As we shall see, it simply adds unnecessary complexity to the monetary-policy rule for no apparent gain. It is conceptually and numerically inferior to the targeting rule, and it is not neutral from a determinacy point of view. In summary, the idea of instrument rules with very large response coefficients is both impractical and pointless.

Section 2 shows a useful analogy between the development of Euler conditions as structural descriptions of consumption choice in the theory of consumption and the development of targeting rules as a structural description of monetary policy in the theory of monetary policy. Section 3 gives

in the policy decision, as other central banks are using forecasts conditional on a constant interest rate. They are not necessarily the central bank's optimal instrument-rate plan and optimal inflation and output-gap forecasts (although I am advocating improvements in that direction, see Svensson [38] and [39]). Thus, the RBNZ's use of an instrument rule in generating its forecasts does not imply that the RBNZ is actually following that instrument rule in setting its instrument rate.

7 Ben and Ed disagree with my statement that one of the problems with a commitment to an instrument rule as a description and prescription of monetary policy "is that a commitment to an instrument rule does not leave any room for judgemental adjustments and extra-model information" [40, p. 442]. They state (section 3): "This claim is difficult for us to understand, since there seem to be various ways in which judgmental adjustments to instrument rule prescriptions could be made. For example, the interest rate instrument could be set above (or below) the rule-indicated value when policymaker judgments indicate that conditions, not adequately reflected in the [central bank's] formal quantitative models, imply different forecasts and consequently call for additional policy tightening (or loosening)." Ben and Ed seem to believe that a commitment is consistent with discretionary adjustments, an obvious contradiction. 
an example of an optimal targeting rule and discusses some of its properties, including its robustness. Section 4 shows that the instrument-rule analogue proposed by Ben and Ed indeed brings high instrument-rate volatility under reasonable information assumptions. Section 5 discusses Ben and Ed's criticism of my definition of "general" targeting rules. I concede that a another term, Walsh's [46] "targeting regimes," may be preferable. Consequently, in future work, I am inclined to use the term "targeting regime" rather than "general targeting rule" and to let "targeting rules," as in this introduction, refer to what I have also called "specific" targeting rules.

\section{An analogy with consumption theory}

In order to view the issue of targeting rules versus instrument rules from a broader descriptive perspective, it is useful to compare with the modeling of consumption in macroeconomics. Several decades ago, it was common to model consumption in period $t, C_{t}$, as a given function of income, $Y_{t}$, the real rate of interest, $R_{t}$, and possibly other variables,

$$
C_{t}=f\left(R_{t}, Y_{t}, \ldots\right)
$$

In the last 25 years, especially after Hall [18], it has become common to model consumption as fulfilling an Euler condition, a first-order condition for optimal consumption choice, which for an additively separable utility function of a representative consumer has the simple form,

$$
\mathrm{E}_{t} \frac{\delta U_{C}\left(C_{t+1}\right)}{U_{C}\left(C_{t}\right)}=\frac{1}{1+R_{t}}
$$

Here, the left side of (2) is the representative consumer's expected marginal rate of substitution of period- $t$ consumption for period- $t+1$ consumption $\left(0<\delta<1\right.$ is a discount factor and $U_{C}\left(C_{t}\right)$ denotes the marginal utility of consumption). The right side is the consumer's marginal rate of transformation of period- $t+1$ consumption into period- $t$ consumption, when the consumer can borrow or lend; that is, the period- $t$ consumption value of consumption in period $t+1$. A loglinear approximation to $(2)$ is

$$
c_{t}=c_{t+1 \mid t}-\sigma\left(r_{t}-\rho\right)
$$

where $c_{t} \equiv \ln C_{t}, c_{t+1 \mid t} \equiv \mathrm{E}_{t} c_{t+1}, \sigma$ is the intertemporal elasticity of substitution, $r_{t} \equiv \ln \left(1+R_{t}\right)$ is the continuously compounded real interest rate, and $\rho \equiv-\ln \delta>0$ is the rate of time preference.

As is well known, a serious problem with modeling consumption as a given consumption function is that this function is not structural but a reduced form. Its properties and parameters depend on 
the whole model of the economy, including the existing shocks and their stochastic properties, the monetary and fiscal policy pursued, and so forth.

In contrast, the consumption Euler condition (2) or (3) is more structural, independent of the rest of the model, and independent of the monetary and fiscal policy pursued. It is a robust, compact, and therefore practical description of optimizing consumption behavior. Indeed, this development of a more microfounded modeling of consumption is an integral part of the rationalexpectations revolution in macroeconomics.

The consumption function can be seen as an instrument rule for consumption behavior, whereas the Euler condition (2) or (3) can be seen as a targeting rule for consumption. When I argue for the adoption of targeting rules rather than instrument rules in modeling monetary policy, I am arguing for a development in the theory of monetary policy that already happened a long time ago in the theory of consumption.

Ben and Ed are attracted to modeling monetary policy with instrument rules rather than targeting rules also for descriptive purposes (section 4). If they were consistent, they should also prefer to model consumption with consumption functions rather than Euler conditions. But they are not consistent. Indeed, it is a great irony that one of Ben and Ed's important contributions to macroeconomics is precisely the introduction of Euler conditions in modeling aggregate demand, for instance, in McCallum and Nelson [26], and, with other newkeynesian pioneers, use a condition such as (3) to derive the newkeynesian aggregate-demand relation.

Do Ben and Ed really believe that a modern central bank is less rational and goal-directed and a worse optimizer than the average consumer? At least they must admit that policymakers in modern central banks have the advantage above the average consumer of being advised by a staff with an increasing number of Ph.D. economists with training in modern macroeconomics and intertemporal optimization. Indeed, an increasing proportion of policymakers themselves are Ph.D. economists with such training!

A structural description of consumption choice is essential in estimating meaningful and robust empirical representations of consumption behavior. In the same way, a structural description of monetary policy is essential in estimating meaningful and robust representations of monetary policy, for instance, parameters of a monetary-policy loss function. Furthermore, a structural description of consumption choice is essential in generating correct predictions in macro models of the consequences of changes in the policy regime. In the same way, a structural description of monetary policy is essential in generating correct predictions in macro models of consequences of 
changes in the monetary-policy regime (in the form of changes in parameters of the monetary-policy loss function), changes in the fiscal-policy regime, changes in the policy regime of other countries, or other changes in the relevant economic or political environment. ${ }^{8}$

\section{An example of an optimal targeting rule}

In order to present an example of a targeting rule, let me consider a variant of the newkeynesian model, a variant used in Svensson and Woodford [44] and Svensson [40], where inflation and the output gap are predetermined. ${ }^{9}$ This variant will also be used in discussing Ben and Ed's instrument-rule analogue in section 4 .

Private-sector "plans" in period $t$ for inflation and the output gap in period $t+1, \pi_{t+1 \mid t}$ and $x_{t+1 \mid t}$, are determined in period $t$ by

$$
\begin{aligned}
\pi_{t+1 \mid t}-\mathrm{E}\left[\pi_{t}\right] & =\delta\left(\pi_{t+2 \mid t}-\mathrm{E}\left[\pi_{t}\right]\right)+\alpha x_{t+1 \mid t}+\alpha_{z} z_{t+1 \mid t} \\
x_{t+1 \mid t} & =x_{t+2 \mid t}-\beta_{r}\left(i_{t+1 \mid t}-\pi_{t+2 \mid t}-r_{t+1 \mid t}^{*}\right)+\beta_{z} z_{t+1 \mid t}
\end{aligned}
$$

The aggregate-supply relation, (4), follows from the first-order condition for Calvo-style profitmaximizing price-setting firms. The firms are assumed to index prices to the long-run average inflation, $\mathrm{E}\left[\pi_{t}\right]$, between the times of optimal price-setting, which implies that the long-run Phillips curve is vertical. The parameter $\delta(0<\delta<1)$ is a discount factor, and $\alpha>0$ is the slope of the short-run Phillips curve. The expression $\alpha_{z} z_{t+1}$ is the inner product of a vector of coefficients, $\alpha_{z}$, and a vector of exogenous random variables, $z_{t+1}$, the "deviation" in period $t+1$, such that $\alpha_{z} z_{t+1}$ is a simple representation of the difference between this simple model and the true model of the transmission mechanism. The deviation may also include any "cost-push" and other shocks. Then, $z_{t+1 \mid t} \equiv \mathrm{E}_{t} z_{t+1}$, where $\mathrm{E}_{t}$ denotes expectations conditional on information available in period $t$, is the private sector's estimate of the deviation, the private sector's "judgment" in period-t. Thus, the one-period-ahead inflation plan depends on expected future inflation, $\pi_{t+2 \mid t} \equiv \mathrm{E}_{t} \pi_{t+2}$, the output-gap plan, $x_{t+1 \mid t}$, and the private-sector judgment, $z_{t+1 \mid t}$.

The aggregate-demand relation, (5), follows from the first-order condition for optimal consumption choice by households. Here, $i_{t+1}$ is the instrument rate set by the central bank in period

\footnotetext{
${ }^{8}$ See Benigno and Benigno [2] and Svensson [41] for examples of the use of targeting rules in discussing international monetary cooperation and transmission of shocks.

9 A predetermined variable depends on the current period's realizations of exogenous variables and previous periods' realizations of endogenous and exogenous variables. Equivalently, a predetermined variable has exogenous one-period-ahead forecast errors, cf. Klein [21].
} 
$t+1, r_{t+1}^{*}$ is an exogenous Wicksellian natural interest rate (the real interest rate in a hypothetical flexprice economy with zero deviation), and $\beta_{r}$ is a positive constant (in the simplest case, the intertemporal elasticity of substitution in consumption). Thus, the one-period-ahead outputgap plan depends on the expected future output gap, $x_{t+2 \mid t}$, the expected one-period-ahead real interest-rate gap, $i_{t+1 \mid t}-\pi_{t+2 \mid t}-r_{t+1 \mid t}^{*}$, and the private-sector judgment, $z_{t+1 \mid t}$ (through the inner product $\left.\beta_{z} z_{t+1 \mid t}\right)$.

Actual inflation and output gap in period $t+1$ will then differ from the plans because of unanticipated shocks to the deviation and natural interest rate,

$$
\begin{aligned}
\pi_{t+1}-\pi_{t+1 \mid t} & =\alpha_{z}\left(z_{t+1}-z_{t+1 \mid t}\right) \\
x_{t+1}-x_{t+1 \mid t} & =\beta_{r}\left(r_{t+1}^{*}-r_{t+1 \mid t}^{*}\right)+\beta_{z}\left(z_{t+1}-z_{t+1 \mid t}\right) .
\end{aligned}
$$

Suppose the central bank conducts flexible inflation targeting and has an intertemporal loss function in period $t$,

$$
\mathrm{E}_{t} \sum_{\tau=0}^{\infty}(1-\delta) \delta^{\tau} L_{t+\tau}
$$

where the period loss is

$$
L_{t}=\frac{1}{2}\left[\left(\pi_{t}-\pi^{*}\right)^{2}+\lambda x_{t}^{2}\right]
$$

where $\pi^{*}$ is the inflation target and $\lambda>0$ is the weight on output-gap stabilization relative to inflation stabilization.

An equilibrium that minimizes the central bank's intertemporal loss function (under commitment in a timeless perspective) will fulfill the first-order condition

$$
\pi_{t+1 \mid t}-\pi^{*}+\frac{\lambda}{\alpha}\left(x_{t+1 \mid t}-x_{t \mid t-1}\right)=0
$$

for all periods $t$ (Svensson and Woodford [44] and Svensson [40]). This condition is the central bank's optimal targeting rule for private-sector inflation and output-gap plans.

Thus, optimal price-setting and consumption choice by the private sector is described by the first-order conditions (4) and (5), and optimal monetary policy is characterized by the first-order condition (8), the central bank's targeting rule. The behaviors of the agents of the model — the firms, the households, and the central bank - are each described by a first-order condition, an attractive symmetry. The central bank's targeting rule is a robust, compact, and, therefore, practical way to describe the optimal monetary policy. In particular, it is robust to the central bank's estimate of the deviation - the central bank's "judgment" - and any additive shocks and their stochastic 
properties, in the sense that the judgment or any shocks do not enter into the targeting rule. The targeting rule (8) is a structural representation of monetary policy to the same extent that the aggregate-supply and aggregate-demand relations are structural representations of private-sector behavior.

As discussed in some detail in Svensson [40], the optimal targeting rule is simply, and fundamentally, a restatement of the standard efficiency condition of equality between the marginal rates of substitution and transformation between the target variables. The target variables - the variables that enter into the loss function - are inflation and the output gap. The marginal rate of substitution between inflation and the output gap follow from the form of the loss function, including the relative weight, $\lambda$. The marginal rate of transformation between inflation and the output gap follows from the form of the aggregate-supply relation, including the slope of the short-run Phillips curve, $\alpha$. Thus, these two parameters appear in the targeting rule. Since the marginal rate of transformation between inflation and the output gap is completely determined by the aggregatesupply relation, the aggregate-demand relation and its parameters do not affect the targeting rule; the targeting rule is, in this case, robust to the aggregate-demand relation.

Thus, fundamentally, the optimal targeting rule is simply the very robust and intuitive relation,

$$
\mathrm{MRS}=\mathrm{MRT}
$$

where MRS and MRT refer, respectively, to the marginal rates of substitution and transformation between the target variables. This relation holds regardless of the particulars of the model, and is in this sense model-independent. Consider the following instruction: "From your loss function, find the marginal rate of substitution between your target variables. From your view of the transmission mechanism of monetary policy, find your marginal rate of transformation between the target variables. Find and implement an instrument rate, or instrument-rate plan, that makes these marginal rates of substitution and transformation equal. Optimal monetary policy is, in principle, as easy as that." What more robust description of optimal monetary policy can you find?

The optimal equilibrium can be solved for by combining the targeting rule, (8), with the aggregate-supply relation, (4). This results in a second-order difference equation that can be solved for the optimal inflation and output-gap plans. Substitution of these plans into the aggregatedemand relation, (5), gives the corresponding optimal instrument-rate plan. Svensson and Woodford [44] and Svensson [40] discuss in some detail how the central bank can implement (8) for private sector plans by "forecast targeting" - constructing and announcing inflation and output-gap pro- 
jections and a corresponding instrument-rate plan that "look good" in the sense of fulfilling the analogue of (8) for inflation and output-gap projections. Ben and Ed do not go into those details.

\section{Volatility from instrument rules?}

Instead, Ben and Ed provide a more precise analysis of their previous claim, in McCallum [24, p. 1493] and McCallum and Nelson [27], that there is a useful instrument-rule analogue of any targeting rule. They discuss two alternatives, the central bank implementing a targeting rule, such as (8), directly, and the central bank replacing the targeting rule (8) with an instrument rule such as

$$
i_{t+1}-r^{*}-\pi_{t+1 \mid t}=\mu\left[\pi_{t+1 \mid t}-\pi^{*}+\frac{\lambda}{\alpha}\left(x_{t+1 \mid t}-x_{t \mid t-1}\right)\right],
$$

where $\mu$ is a large positive number. The idea with (9) is that, for a large $\mu$, there would be an equilibrium fulfilling (4), (5) and (9), where the term in the bracket on the right side of (9) is close to zero and the instrument rate on the left side is close to the optimal instrument rate. Therefore, this instrument rule would result in an equilibrium close to the optimal one.

This is indeed the case, under some circumstances. But what is the point with Ben and Ed's instrument rule? First, for any finite $\mu$, the corresponding equilibrium is no longer optimal but only close to optimal. Everything else equal, optimal is better. Second, equation (9) is a more complex equilibrium condition than (8). Everything else equal, simplicity is better than complexity. Third, the targeting rule (8) has the attractive conceptual property of corresponding to a standard efficiency condition, the equality of the marginal rates of substitution and transformation between the target variables. The instrument rule (9) has no such intuitive interpretation. There is hence a conceptual disadvantage to (9). Fourth, it is no longer possible to solve for the optimal inflation and output-gap plans by combining (9) only with the aggregate-supply relation, (4). Because the instrument rate enters, (9) must now be combined also with the aggregate-demand relation, (5), leading to a higher-order system of difference equations. There is hence a computational disadvantage to (9). Fifth, as discussed in some detail in Svensson and Woodford [44], modifying targeting or instrument rules in this way often affects the determinacy properties of forward-looking models and is therefore not innocuous.

Finally, as pointed out in Svensson and Woodford [44] and Svensson [40], a high response

coefficient, $\mu$, can lead to instrument-rate volatility under realistic information assumptions of some central-bank mistakes or even just rounding errors. From a practical perspective, a very high 
response coefficient is a bizarre idea and would cause serious problems, except under very strange circumstances, as we shall see.

Thus, for several reasons, the instrument rule (9) is inferior to the targeting rule (8). I have not found any arguments by Ben and Ed in favor of (9). Ben and Ed might have thought that (9) would be easier to implement that (8). But a more precise discussion of the implementation reveals that this is not so: aside from the issue of volatility, they are equally difficult or easy to implement..$^{10}$

In order to examine the case of central-bank mistakes, Ben and Ed consider the targeting rule with a random error, $e_{t}$,

$$
\pi_{t+1 \mid t}-\pi^{*}+\frac{\lambda}{\alpha}\left(x_{t+1 \mid t}-x_{t \mid t-1}\right)+e_{t}=0
$$

and the alternative instrument rule,

$$
i_{t+1}=r^{*}+\pi_{t+1 \mid t}+\mu\left[\pi_{t+1 \mid t}-\pi^{*}+\frac{\lambda}{\alpha}\left(x_{t+1 \mid t}-x_{t \mid t-1}\right)+e_{t}\right]
$$

We can (in a more simple discussion of implementation than in footnote 10) interpret the instrument rule as the central bank attempting to observe private-sector plans $\pi_{t+1 \mid t}$ and $x_{t+1 \mid t}$ in period $t$, using its previous observation of $x_{t \mid t-1}$ in period $t-1$, in order to calculate the expression

$$
\pi_{t+1 \mid t}-\pi^{*}+\frac{\lambda}{\alpha}\left(x_{t+1 \mid t}-x_{t \mid t-1}\right)
$$

for use in (9). In doing this, the central bank introduces a random error, $e_{t}$.

Ben and Ed then actually calculate the rational-expectations equilibrium under the assumption that the error $e_{t}$ is immediately observed and known to both the central bank and the private sector in period $t$, before the instrument rate $i_{t+1}$ is announced. Suppose that the error is positive, $e_{t}>0$. Everything else equal, it would raise the instrument rate by $\mu e_{t}>0$, where $\mu$ is a large number. The private sector, realizing this, immediately responds by lowering their inflation and output-gap plans, $\pi_{t+1 \mid t}$ and $x_{t+1 \mid t}$, according to (4) and (5). Indeed, the private sector is assumed to instantaneously adjust their plans so as to bring about the rational-expectations equilibrium for

\footnotetext{
10 The instrument rule (9) is an implicit instrument rule, meaning that it is an equilibrium condition, where the variables on the right side depend on the instrument rate; there is a simultaneity aspect that needs to be handled. In contrast, an explicit instrument rule makes the instrument a function of predetermined variables, which are hence independent of the instrument. Hence, the implementation of an explicit instrument rule is simply a matter of observing the predetermined variables and calculating and announcing the corresponding instrument value. Implicit instrument rules and targeting rules are both equilibrium conditions, with variables that are simultaneously determined. Their implementation is hence different from, and more complicated than, that of an explicit instrument rule. As discussed in detail in Svensson and Woodford [44] and Svensson [40], their implementation requires the central bank to use its model of the transmission mechanism, make projections of the variables included in the target rule or implicit instrument rule, and find the combination of instrument and target-variable projections that fulfill the target rule or implicit instrument rule. Announcing these projections and implementing the instrument-rate path will then induce the private sector to behave according to the desired equilibrium.
} 
a known error $e_{t}$. Furthermore, the central bank is then assumed to observe the adjusted plans, and then calculate and implement the equilibrium instrument rate according to (11). The result is that the equilibrium instrument rate increases by much less than $\mu e_{t}$. Indeed, with a large $\mu,(10)$ is approximately fulfilled, so the equilibrium resulting from (11) ends up being similar to the equilibrium resulting from (10) (disregarding any determinacy issues). In particular, the error introduces no more volatility for the instrument rule (11) than for the targeting rule (10).

But the idea that the central bank and the private sector immediately observes the error in period $t$ is strange, to say the least. If the central bank observes the error, why does it not immediately correct the sum (12) so as to eliminate the error and instead implement (9) without any error?

Assume, more realistically, that the error is not immediately observed by the central bank or the private sector. Instead, the private sector first forms its plans under the assumption of a zero expected central-bank error (assuming that the error is iid and has a zero mean). The central bank then imperfectly observes those plans, introduces the (measurement) error, and announces the corresponding instrument rate, $i_{t+1}$, for period $t+1$. Assume, realistically, that the instrument rate can only be announced once in each period. In this case, the error hits the instrument rate with the full force of $\mu e_{t}$. If the private sector knows its own plans and how the central bank calculates the instrument rate, the private sector will be able to infer the error when it learns $i_{t+1}$. If the announcement is early - in period $t$ rather than in period $t+1$ - the private sector may be able to adjust its plans after the announcement, and the error will have an impact on the plans. If the announcement is late - in period $t+1$ - the private-sector plans cannot be adjusted, and the plans for inflation and the output gap are unaffected by the error. But, in either case, the error still affects the instrument rate with the full magnitude $\mu e_{t}$. Under this realistic information assumption of the error not being immediately observed by the central bank and the private sector, a large $\mu$ will indeed introduce high volatility of the instrument rate, precisely as argued in Svensson and Woodford [44] and Svensson [40]. Central bankers, beware of Ben and Ed's instrument rule!

Even something as trivial as a small rounding error could be problematic. Suppose that the central bank rounds off its calculation of (12) to one decimal percentage point, that is 10 basis points. This would introduce a uniformly distributed absolute error with a mean of 2.5 basis points. With $\mu=50$, the corresponding mean absolute error of the instrument rate is 125 basis points - a sizeable error, especially since instrument changes are seldom larger than 50 basis points. In real-world monetary policy, the error $e_{t}$ could be substantially larger, say a mean absolute error 
of 50 basis points ( 0.5 percent) or more. With $\mu=50$, this would lead to a huge mean absolute instrument-rate error of 2500 basis points or more.

Ben and Ed defend their informational assumptions by pointing out, in the appendix of [28], that Svensson and Woodford [44] and Svensson [40] make information assumptions that imply that any error would be immediately revealed. But Svensson and Woodford [44] and Svensson [40] do not attempt to provide any detailed discussion of such central-bank errors and related realistic information assumptions. This detail is provided here, instead. One might have wished that Ben and Ed would have considered more realistic information assumptions on their own, since these assumptions are so crucial to their proposition. Indeed, realistic assumptions completely contradict their proposition.

Thus, the criticism in Svensson and Woodford [44] and Svensson [40] of Ben and Ed's proposed instrument rule stands up to scrutiny: An instrument rule such as (9) with a very large response coefficient is a purely academic construction and completely impractical for any real-world monetary policy. The first five items in the list above provide additional reasons for the inferiority of such instrument rules compared to targeting rules.

\section{$5 \quad$ General targeting rules?}

The discussion here has so far concerned "specific" targeting rules, in the terminology of Svensson and Woodford [44] and Svensson [40]. Those papers also define "general" targeting rules for monetary policy as an operational formulation of the objectives for monetary policy, for instance, in the form of listing the target variables and the corresponding target levels and specifying the loss function to be minimized. Ben and Ed clearly find this definition confusing and not useful. My idea behind the definition is that the instruction to "specify your loss function in an operational way, construct forecasts of the target variables, and select and implement an instrument rate or an instrument-rate path such that the forecasts minimize the loss function" is such a specific instruction to a central bank that it deserves to be called a "rule," in the common (and dictionary, see Merriam-Webster [30]) sense of a rule being "a prescribed guide for conduct or action." ${ }^{11}$ Perhaps it had been better, and caused less confusion, to refer to this as "general targeting" instead of a

\footnotetext{
$[37]$.

11 This is the idea behind word "rule" in the title "Inflation Targeting as a Monetary Policy Rule" of Svensson
} 
"general targeting rule." ${ }^{12}$ Walsh [46] uses the term "targeting regime," which arguably is better. ${ }^{13}$

The idea with a particular terminology and particular definitions is, of course, that it shall contribute to more useful and precise discussion and analysis. I am inclined to concede that the term "general targeting rule" has not been successful and that Walsh's term "targeting regime" is better. Consequently, I am inclined to use that terminology in the future, and to let "targeting rules" refer only to what I have previously called "specific" targeting rules. ${ }^{14}$

\section{Conclusion}

Counter to what Ben and Ed seem to take as granted, there is no reason at all to limit a study of robust simple monetary-policy rules to instrument rules; simple targeting rules may have more desirable properties. Furthermore, targeting rules are a compact, robust, structural and, therefore, practical representation of goal-directed monetary policy. From a descriptive point of view, they amount to the same development in the theory of monetary policy as the consumption Euler conditions in the theory of consumption. Optimal targeting rules express the intuitive optimality condition of equality between the marginal rates of substitution and transformation of the target variables. Regardless of Ben and Ed's scepticism in McCallum and Nelson [28], targeting rules for the analysis of monetary policy have arrived and are, as indicated by the long list of papers and books mentioned in the introduction, likely to stay. In particular, Ben and Ed's proposed instrument-rule analogue to any targeting rule will, under realistic information assumptions, lead to very high instrument-rate volatility and is also for other reasons inferior to the targeting rule.

\footnotetext{
${ }^{12}$ It should not be necessary to state that "targeting," in the sense of "achieving a target," is best seen as equivalent to minimizing a loss function that is increasing in the deviation between the target variables and the target levels. That is, targeting and target variables refer to a loss function to be minimized and the arguments in that loss function.

The literature has previously by "targeting variable $X$ " sometimes meant putting variable $X$ in the instrument rule. In order to avoid confusion, this has better be called "responding to variable $X$." Generally, the best way to target variable $X$, in the sense of minimizing a loss function increasing in deviations of variable $X$ from its target level, is to respond, in the explicit instrument rule, to all the determinants of variable $X$. Even if inflation and the output gap are the only target variables, there are usually many more variables determining future inflation and the output gap, and it is optimal to respond to all of those.

Generally, the mapping from a loss function to the optimal reaction function, the optimal explicit instrument rule, is quite complex, and the response coefficients of the optimal explicit instrument rule are complicated and sometimes nonmonotonic functions of the parameters of the loss function and the whole model. The size of the response coefficient of a variable is not an indicator of the weight of the variable in the loss function.

${ }^{13}$ In any case, there is always a close relation between a (specific) targeting rule in the form of some scalar expression $T_{t}\left(\pi_{t}, x_{t}\right)=0$ and a loss function of the form $L_{t}=\left[T_{t}\left(\pi_{t}, x_{t}\right)\right]^{2}$, since the former is a first-order condition for a minimum of the latter.

${ }^{14}$ For a situation when a commitment to an optimal (specific) targeting rule is not possible, Svensson and Woodford [44] and Svensson [40] discuss a "commitment to continuity and predictability," which involves minimizing the centralbank loss function while taking into account the cost of deviating from previously announced forecasts. This will make optimization under discretion result in the optimal outcome under commitment. Strangely, Ben and Ed describe this mechanism that induces the central bank to keep previous promises as "the central bank describing its objectives dishonestly to the public" (section 2).
} 


\section{References}

[1] Aizenman, Joshua, and Jacob A. Frenkel (1986), "Targeting Rules for Monetary Policy," Economics Letters 21, 183-187.

[2] Benigno, Pierpaolo, and Gianluca Benigno (2003), "Designing Targeting Rules for International Monetary Policy Cooperation," European Central Bank Working Paper No. 279.

[3] Benigno, Pierpaolo, and Michael Woodford (2003), "Optimal Monetary and Fiscal Policy: A Linear-Quadratic Approach," NBER Macroeconomics Annual 2003 18, 271-333.

[4] Benigno, Pierpaolo, and Michael Woodford (2004), "Optimal Stabilization Policy When Wages and Prices are Sticky: The Case of a Distorted Steady State," working paper.

[5] Bernanke, Ben S., and Michael Woodford (1997), "Inflation Forecasts and Monetary Policy," Journal of Money, Credit, and Banking 29, 654-684.

[6] Bernanke, Ben S., and Michael Woodford, eds. (2004), The Inflation Targeting Debate, Chicago University Press, forthcoming.

[7] Black, Richard, Vincenzo Cassino, Aaron Drew, Eric Hansen, Benjamin Hunt, David Rose, and Alasdair Scott (1997), "The Forecasting and Policy System: The Core Model," Research Paper No. 43, Reserve Bank of New Zealand, Wellington.

[8] Brash, Donald T. (2001), "Making Monetary Policy: A Look behind the Curtains," speech in Christchurch, January 26, 2001.

[9] Bryant, Ralph C., Peter Hooper, and Catherine L. Mann, eds. (1993), Evaluating Policy Regimes: New Research in Empirical Macroeconomics, The Brookings Institution, Washington D.C.

[10] Cecchetti, Stephen G. (1998), "Central Bank Policy Rules: Conceptual Issues and Practical Considerations," in Helmut Wagner, ed., Current Issues in Monetary Economics, PhysicaVerlag, Heidelberg, 121-140.

[11] Cecchetti, Stephen G. (2000), "Making Monetary Policy: Objectives and Rules," Oxford Review of Economic Policy 16(4), 43-59. 
[12] Cecchetti, Stephen G., and Junhan Kim (2003), "Inflation Targeting, Price-Path Targeting, and Output Variability," in Bernanke and Woodford [6], forthcoming.

[13] Evans, George W., and Seppo Honkapohja (2004), "Monetary Policy, Expectations and Commitment," working paper.

[14] Giannoni, Marc P., and Michael Woodford (2003a), "Optimal Interest-Rate Rules: I. General Theory," NBER Working Paper No. 9419.

[15] Giannoni, Marc P., and Michael Woodford (2003b), "Optimal Interest-Rate Rules: II. Applications," NBER Working Paper No. 9420.

[16] Giannoni, Marc P., and Michael Woodford (2003), "Optimal Inflation Targeting Rules," in Bernanke and Woodford [6], forthcoming.

[17] Goodhart, Charles A.E. (2000), "The Inflation Forecast," working paper, London School of Economics.

[18] Hall, Robert E. (1978), "Stochastic Implications of the Life Cycle-Permanent Income Hypothesis: Theory and Evidence," Journal of Political Economy 86, 971-987.

[19] Hansen, Lars Peter, and Thomas J. Sargent (2003), "Robust Control of Forward-Looking Models," Journal of Monetary Economics 50, 581-604.

[20] Hansen, Lars Peter, and Thomas J. Sargent (2004), Robust Control and Economic Model Uncertainty, Princeton University Press.

[21] Klein, Paul (2000), "Using the Generalized Schur Form to Solve a Multivariate Linear Rational Expectations Model," Journal of Economic Dynamics and Control 24, 1405-1423.

[22] Kuttner, Kenneth N. (2004), "The Role of Policy Rules in Inflation Targeting," working paper, www.oberlin.edu/economic/faculty/kuttner.htm.

[23] McCallum, Bennett T. (1988), "Robustness Properties of a Rule for Monetary Policy," Carnegie-Rochester Conference Series on Public Policy 29, 173-204.

[24] McCallum, Bennett T. (1999), "Issues in the Design of Monetary Policy Rules," in Taylor, John B., and Michael Woodford, eds., Handbook of Macroeconomics, Volume 1C, North-Holland, $1483-1530$. 
[25] McCallum, Bennett T., and Edward Nelson (1999a), "Nominal Income Targeting in an OpenEconomy Optimizing Model," Journal of Monetary Economics 43, 553-578.

[26] McCallum, Bennett T., and Edward Nelson (1999b), "An Optimizing IS-LM Specification for Monetary Policy and Business Cycle Analysis," Journal of Money, Credit, and Banking 31, 296-316.

[27] McCallum, Bennett T., and Edward Nelson (2000), "Timeless Perspective vs. Discretionary Monetary Policy in Forward-Looking Models," Federal Reserve Bank of St. Louis Review 86(2), $43-56$.

[28] McCallum, Bennett T., and Edward Nelson (2004), "Targeting vs. Instrument Rules for Monetary Policy," Federal Reserve Bank of St. Louis Working Paper 2004-011A.

[29] Meltzer, Allan H. (1987), "Limits of Short-Run Stabilization Policy," Economic Inquiry 25, $1-13$.

[30] Merriam-Webster (1996), Webster's Tenth New Collegiate Dictionary, Merriam-Webster, Springfield, MA.

[31] Mishkin, Frederic S. (2003), "The Role of Output Stabilization in the Conduct of Monetary Policy," International Finance 5, 213-227.

[32] Onatski, Alexei, and Noah Williams (2004), "Empirical and Policy Performance of a ForwardLooking Monetary Model," www.princeton.edu/ noahw.

[33] Preston, Bruce (2004), "Adaptive Learning and the Use of Forecasts in Monetary Policy," working paper.

[34] Rudebusch, Glenn D., and Lars E.O. Svensson (1999), "Policy Rules for Inflation Targeting," in Taylor [45], 203-246.

[35] Sims, Christopher A. (1980), "Macroeconomics and Reality," Econometrica 48, 1-48.

[36] Svensson, Lars E.O. (1997), "Inflation Forecast Targeting: Implementing and Monitoring Inflation Targets," European Economic Review 41, 1111-1146.

[37] Svensson, Lars E.O. (1999), "Inflation Targeting as a Monetary Policy Rule," Journal of Monetary Economics 43, 607-654. 
[38] Svensson, Lars E.O. (2001a), "Independent Review of the Operation of Monetary Policy: Report to the Minister of Finance," www.princeton.edu/ svensson.

[39] Svensson, Lars E.O. (2001b), "The Inflation Forecast and the Loss Function," in Paul Mizen, ed., Central Banking, Monetary Theory and Practice: Essays in Honour of Charles Goodhart, Edward Elgar.

[40] Svensson, Lars E.O. (2003a), "What is Wrong with Taylor Rules? Using Judgment in Monetary Policy through Targeting Rules," Journal of Economic Literature 41, 426-477.

[41] Svensson, Lars E.O. (2003b), "The Magic of the Exchange Rate: Optimal Escape from a Liquidity Trap in Small and Large Open Economies," working paper, www.princeton.edu/ svensson.

[42] Svensson, Lars E.O. (2004), "Optimization under Discretion and Commitment, and Targeting Rules and Instrument Rules: Lecture Notes," www.princeton.edu/ svensson.

[43] Svensson, Lars E.O, Kjetil Houg, Haakon Solheim, and Erling Steigum (2002), "An Independent Review of Monetary Policy and Institutions in Norway," Norges Bank Watch 2002, Centre for Monetary Economics, Norwegian School of Management BI, www.princeton.edu/ svensson.

[44] Svensson, Lars E.O., and Michael Woodford (2004), "Implementing Optimal Policy through Inflation-Forecast Targeting," in Bernanke and Woodford [6], forthcoming.

[45] Taylor, John B., ed. (1999), Monetary Policy Rules, Chicago University Press.

[46] Walsh, Carl E. (2003), Monetary Theory and Policy, 2nd edition, MIT Press, Cambridge, MA.

[47] Walsh, Carl E. (2004a), "Parameter Misspecification and Robust Monetary Policy Rules," working paper, econ.ucsc.edu/ $\sim$ walshc.

[48] Walsh, Carl E. (2004b), "Robustly Optimal Instrument Rules and Robust Control: An Equivalence Result," Journal of Money, Credit, and Banking, forthcoming, econ.ucsc.edu/ ${ }^{\text {walshc. }}$

[49] Woodford, Michael (2003a), "Inflation Targeting and Optimal Monetary Policy," working paper, www.princeton.edu/ woodford. 
[50] Woodford, Michael (2003b), Interest Rates and Prices: Foundations of a Theory of Monetary Policy, Princeton University Press. 